\title{
Avaliação de riscos ambientais no Aeroporto Internacional de Viracopos, Campinas (SP)
}

\author{
Thales Andrés Carra ${ }^{1}$, Fabiano Tomazini da Conceição ${ }^{2 *}$, Bruno Bernardes Teixeira ${ }^{3}$
}

\begin{abstract}
Resumo Considerando o contexto atual de valorização da questão ambiental, o objetivo deste trabalho foi propor e aplicar indicadores para avaliação de riscos ambientais em aeroportos. Para tanto, foram elaborados 19 indicadores sobre armazenamento e manipulação de substâncias perigosas. Tais indicadores representam cinco condições que receberam uma pontuação desde o pior cenário (nível 1) até a condição ideal (nível 5). Os indicadores foram aplicados, em um estudo de caso, no Aeroporto Internacional de Viracopos, Campinas (SP). Os resultados obtidos no estudo de caso apresentaram um desempenho médio equivalente a 2,3 em uma escala de 1 a 5 , caracterizando o desempenho como crítico. Posteriormente, foram analisadas as principais fragilidades no gerenciamento de risco ambiental do Aeroporto Internacional de Viracopos, bem como a identificação de boas práticas e soluções ambientais para o desenvolvimento das atividades do empreendimento. Dentre as estratégias de manejo sugeridas, destaca-se a adequação de áreas para armazenamento de substâncias perigosas. De maneira geral, pode-se inferir que os indicadores propostos neste trabalho permitiram avaliar o desempenho na gestão dos riscos ambientais no Aeroporto Internacional de Viracopos e propor ações que visam prevenir, controlar, corrigir e mitigar os impactos ambientais decorrentes de sua operacionalidade.
\end{abstract}

Palavras-chave: riscos ambientais; aeroportos; gerenciamento ambiental.

\begin{abstract}
Evaluation of environmental risk at Viracopos International Airport, Campinas (SP). Considering the current context of environmental concern, the main purpose of this research was to develop and apply indicators to evaluate the environmental risk for airports. As a result, 19 indicators related to storage and handling dangerous substances were created. These indicators represent five conditions varying from the worst (level 1) to the ideal condition (level 5). The indicators were applied, as a study of case, at Viracopos International Airport, Campinas (SP). The results showed a medium performance of 2.3, using a scale raging from 1.0 to 5.0, characterized as 'critical'. Then, the indicators were analyzed to determine the major weaknesses related to the environmental management at Viracopos International Airport, as well as to identify good practices and solutions. Among the suggested management strategies, we highlight the suitability of areas for storage of dangerous substances. In general, it can be inferred that the indicators proposed in this paper to evaluate the performance in the management of environmental risks at the Viracopos International Airport and propose actions to prevent, monitor, correct, and mitigate the environmental impacts of its operations.
\end{abstract}

Keywords: environmental risk; airport; environmental management.

INTRODUÇÃO Risco ambiental pode ser definido como uma situação de perigo, perda ou dano, ao homem e as suas propriedades, em razão da possibilidade de ocorrência de acidentes, induzidos ou não (Oliveira \& Brito 1998). Os acidentes industriais ocorridos na década de 1980 contribuíram de maneira significativa para despertar a atenção das autoridades governamentais, da indústria e da sociedade como um todo, no sentido de buscar meios para a prevenção desses episódios que comprometem a segurança das pessoas e a qualidade do meio ambiente (CETESB 2003).

$\mathrm{O}$ risco de um aeroporto para a comunidade e o meio ambiente, internos e externos aos limites do empreendimento, está diretamente associado às características das substâncias químicas manipuladas, suas respectivas quantidades e as características e vulnerabilidade do local e região onde o aeroporto está localizado. Além do ruído e da poluição atmosférica, estudos revelam que as comunidades no entorno de aeroportos estão expostas a outros tipos de riscos, como contaminação do solo por hidrocarbonetos (Johson et al. 1996, Ray et al. 2008) e acidentes aéreos (Ale \& Piers 2000).

Dessa maneira, os aeroportos são empreendimentos que podem apresentar índices de risco acima dos limites toleráveis, já que envolvem a manipulação de grandes volumes de combustíveis para

\footnotetext{
${ }^{1}$ Programa de Pós-graduação em Geologia Regional, Instituto de Geociências e Ciências Exatas - IGCE, Universidade Estadual Paulista Júlio de Mesquita Filho - UNESP, Rio Claro (SP), Brasil. E-mail: thalescarra@gmail.com

${ }^{2}$ IGCE, UNESP - Rio Claro (SP), Brasil. E-mail: ftomazini@rc.unesp.br

${ }^{3}$ Programa de Pós-Graduação em Engenharia Civil, Faculdade de Engenharia Civil, Arquitetura e Urbanismo da Universidade Estadual de Campinas - UNICAMP, Campinas (SP), Brasil. E-mail: bru_bt@yahoo.com.br

*Autor correspondente
} 
aviação, gás liquefeito de petróleo (GLP) e cargas perigosas. Além disso, são locais onde se desenvolvem atividades de manutenção com o uso de óleos e fluídos hidráulicos, passíveis de contaminação e explosão, bem como operações de fumigação com brometo de metila em Terminais de Cargas. Partindo desse pressuposto e dependendo das características do local, os aeroportos, como um todo, ou apenas as instalações de armazenamento de combustível para aviação, são objetos de Análise de Risco, que em geral é um documento integrante do licenciamento ambiental e contempla o levantamento quantitativo dos riscos.

Entretanto, independentemente da elaboração de uma Análise de Risco, os aeroportos devem ser operados e mantidos dentro de padrões considerados toleráveis de riscos ambientais, razão pela qual um Programa de Gerenciamento de Riscos (PGR) deve ser implementado. O PGR deve ter como meta prevenir, mitigar e controlar os riscos possíveis e prováveis de acidentes que possam comprometer a saúde e a segurança da população, bem como do meio ambiente como um todo. Dentre as premissas de um PGR inclui-se um Plano de Ação de Emergência que define as responsabilidades, as diretrizes e as informações que visam à adoção de procedimentos técnicos e administrativos estruturados de forma a propiciar respostas rápidas e eficientes em situações emergenciais (CETESB 2003).

Paralelamente à Legislação Ambiental, existe a obrigação por parte da Organização Internacional da Aviação Civil (OACI) de elaborar um Plano de Emergência em Aeroportos (OACI 1991). Tal plano contempla, por exemplo, os aspectos referentes às emergências com produtos perigosos e incêndio, mas com o enfoque maior nas questões de segurança operacional do que de proteção ao meio ambiente.

Considerando o armazenamento temporário de cargas radioativas e os procedimentos operacionais e de manutenção dos equipamentos de raios-X para inspeção de bagagens, os aeroportos devem dispor também de um Plano de Radioproteção. Este é utilizado de maneira a estabelecer os requisitos mínimos necessários a serem atendidos para proteção do homem e do meio ambiente, contra os possíveis efeitos adversos causados pela radiação.

Além disso, medidas como a instalação de sistemas para a separação de água e óleo na drenagem de pistas e pátios, nas áreas de abastecimento de aeronaves e veículos e nos locais em que são realizadas manutenções de equipamentos e aeronaves, são essenciais em aeroportos para a redução dos riscos ao meio ambiente. No presente trabalho esse tema está associado aos riscos de contaminação do solo e da água, bem como da saúde e da integridade física da população, causados pelo acondicionamento, transporte, manuseio e uso de produtos considerados perigosos.

Diante desse cenário e considerando o contexto atual de preservação ambiental, surge a necessidade da administração aeroportuária, bem como das partes interessadas serem alertadas para os diferentes aspectos ambientais associados ao gerenciamento de riscos nos aeroportos, de forma que possam atuar pronta e objetivamente no controle e minimização de seus impactos. $\mathrm{O}$ uso de indicadores ambientais torna-se um instrumento que auxilia a administração aeroportuária a identificar os aspectos ambientais significativos e as oportunidades para melhorar a gestão dos riscos, possibilitando a apresentação desses resultados de maneira acessível ao público e aos responsáveis pelas tomadas de decisão.

Através dos indicadores, pode-se então coletar os dados para avaliar o status do desempenho da gestão dos riscos ambientais e identificar onde as melhorias são necessárias, contemplando um processo contínuo que segue um modelo gerencial PDCA [Planejar (Plan) - Fazer (Do) - Checar (Check) - Agir (Act) (ABNT 2004). Entretanto, a grande dificuldade em se avaliar o desempenho na gestão dos riscos ambientais em um aeroporto constitui-se na elaboração dos indicadores, na indisponibilidade de dados para comparação com outras empresas e na dificuldade em se obter um desempenho global. Assim, o presente estudo tem como objetivo desenvolver e aplicar indicadores para avaliar o desempenho do gerenciamento de riscos ambientais no Aeroporto Internacional de Viracopos, Campinas (SP), bem como propor medidas para a melhoria contínua do empreendimento.

\section{CARACTERIZAÇÃO DA ÁREA DE ESTUDO}

Localizado a aproximadamente $18 \mathrm{~km}$ do centro de Campinas e $95 \mathrm{~km}$ do centro de São Paulo, o Aeroporto Internacional de Viracopos(Fig. 1), Campinas (SP), foi fundado em 1930, a partir da construção de uma pista de pouso rudimentar, utilizada pelos paulistas na Revolução de 1932 (Walm 2008). Segundo o Plano Diretor do Município de Campinas, o aeroporto localiza-se na chamada Macrozona 7, intitulada Área de Influência Aeroportuária (AIA). Essa área inclui tanto o aeroporto, quanto sua área de expansão, além dos bairros do seu entorno, e está sujeita aos impactos das operações aeroportuárias. Parte dessa área é 
caracterizada como rural e apresenta infraestrutura urbana precária, reduzido potencial para expandir o saneamento básico, restrições ambientais para captação na Bacia do Rio Capivari - Mirim, onde o aeroporto está inserido, e sistema viário descontínuo (Struchel et al. 2008).

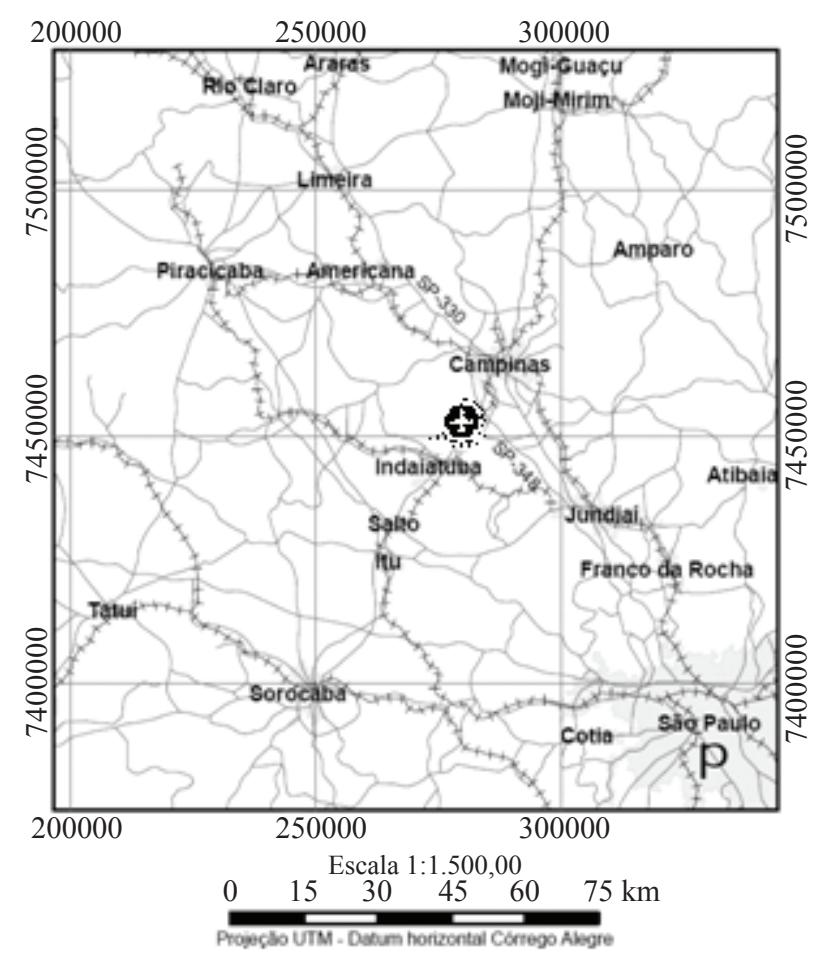

Figura 1 - Localização do Aeroporto Internacional de Viracopos (CAMPINAS 2006).
Após diversas obras e instalações de equipamentos, o Aeroporto de Viracopos foi homologado para operações internacionais em 1960. Desde 1995, a Empresa Brasileira de Infraestrutura Aeroportuária (INFRAERO) realiza investimentos para melhorias nos terminais de cargas e passageiros. A primeira fase foi entregue no primeiro semestre de 2004, quando o aeroporto passou a contar com novas salas de embarques, desembarques, áreas públicas e concessões comerciais. Em 2005, foi entregue a ampliação do terminal de passageiros. Como resultado dos investimentos e considerando o esgotamento da capacidade do Aeroporto de São Paulo/Congonhas e do Aeroporto Internacional de São Paulo/Guarulhos, em dezembro de 2008, Viracopos passou a operar mais vôos de passageiros. Este fato alavancou o número de embarque no aeroporto, quintuplicando o número de passageiros embarcados de 2008 a 2010, conforme ilustra a Fig. 2 (INFRAERO 2011).

Atualmente, o Aeroporto Internacional de Viracopos é o $12^{\circ}$ em termos de embarque de passageiros, o segundo maior aeroporto do Brasil em termos de movimentação de cargas e o maior em termos de valor agregado, o que faz com que assuma grande importância na cadeia de produção da Região Metropolitana de Campinas (INFRAERO 2011). Além disso, as projeções do Plano Diretor

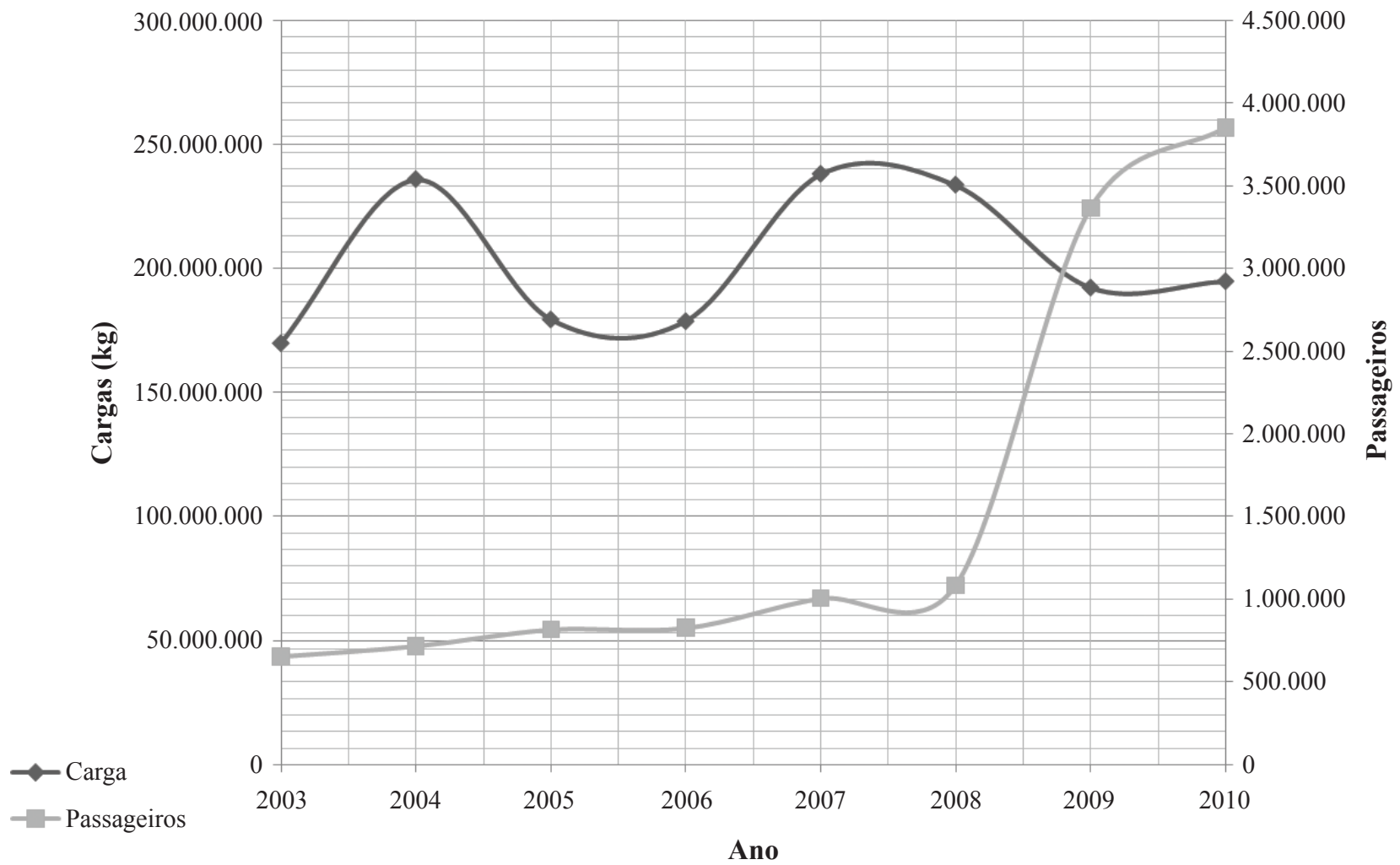

Figura 2 - Evolução do movimento de carga e passageiros do Aeroporto Internacional de Viracopos entre os anos de 2003 a 2010 (INFRAERO 2011). 
do aeroporto colocam Viracopos como o maior Aeroporto da América Latina, com previsão para o atendimento de mais de 50 milhões de passageiros e mais de 2,3 milhões de toneladas de carga até 2025, ou seja, aproximadamente dez vezes a mais o movimento de 2010 (Walm 2008).

Com relação aos recursos hídricos, o Aeroporto Internacional de Viracopos está inserido na bacia do Rio Capivari-Mirim, integrante da Unidade de Gerenciamento de Recursos Hídricos $n^{\circ} 5$ Piracicaba/Capivari/Jundiaí (PCJ), localizada na região leste do Estado de São Paulo, reunindo as Bacias Hidrográficas dos rios Piracicaba, Capivari e Jundiaí. A bacia do Rio Capivari, com aproximadamente 180 $\mathrm{km}$ de extensão, situa-se na margem direita do Rio Tietê, sendo os rios Capivari e Capivari-Mirim, da nascente até sua foz, seus principais componentes. Sua área é caracterizada pela intensa ocupação por atividades antrópicas, com predomínio do cultivo da cana-de-açúcar (cerca de $40 \%$ do total da área), seguido pelas pastagens, cultivo de milho, café e feijão, além da ocorrência de reflorestamentos e atividades hortifrutigranjeiras (Struchel et al. 2008). São significativas na bacia as áreas urbanas densamente ocupadas existentes a montante da área do empreendimento. Os principais usos da água são para abastecimento público, industrial e irrigação de plantações. A área do aeroporto é atravessada, em sua porção central, pelo Córrego Ribeirão Viracopos que deságua na margem esquerda do Rio Capivari-Mirim, conforme ilustra a Fig. 3.

\section{MÉTODO DE AVALIAÇÃO DE RISCOS} AMBIENTAIS Para o monitoramento e mensuração dos riscos ambientais de um aeroporto, é proposto neste trabalho uma metodologia baseada na norma NBR 14.031/2004 e na Metodologia do Carbono Social $^{\mathrm{TM}}$ (Social Carbon) (Rezende \& Merlin 2003, Santos 2008). Essa metodologia baseia-se na elaboração e aplicação de indicadores que priorizam os critérios ambientais e tem como objeto a gestão de riscos em aeroportos. A descrição e aplicação da metodologia de avaliação foram desenvolvidas em quatro etapas seguindo o modelo gerencial PDCA, como ilustrado na Fig. 4.

A primeira etapa (planejar) consiste em selecionar e elaborar os indicadores com base no levantamento dos principais aspectos relacionados ao

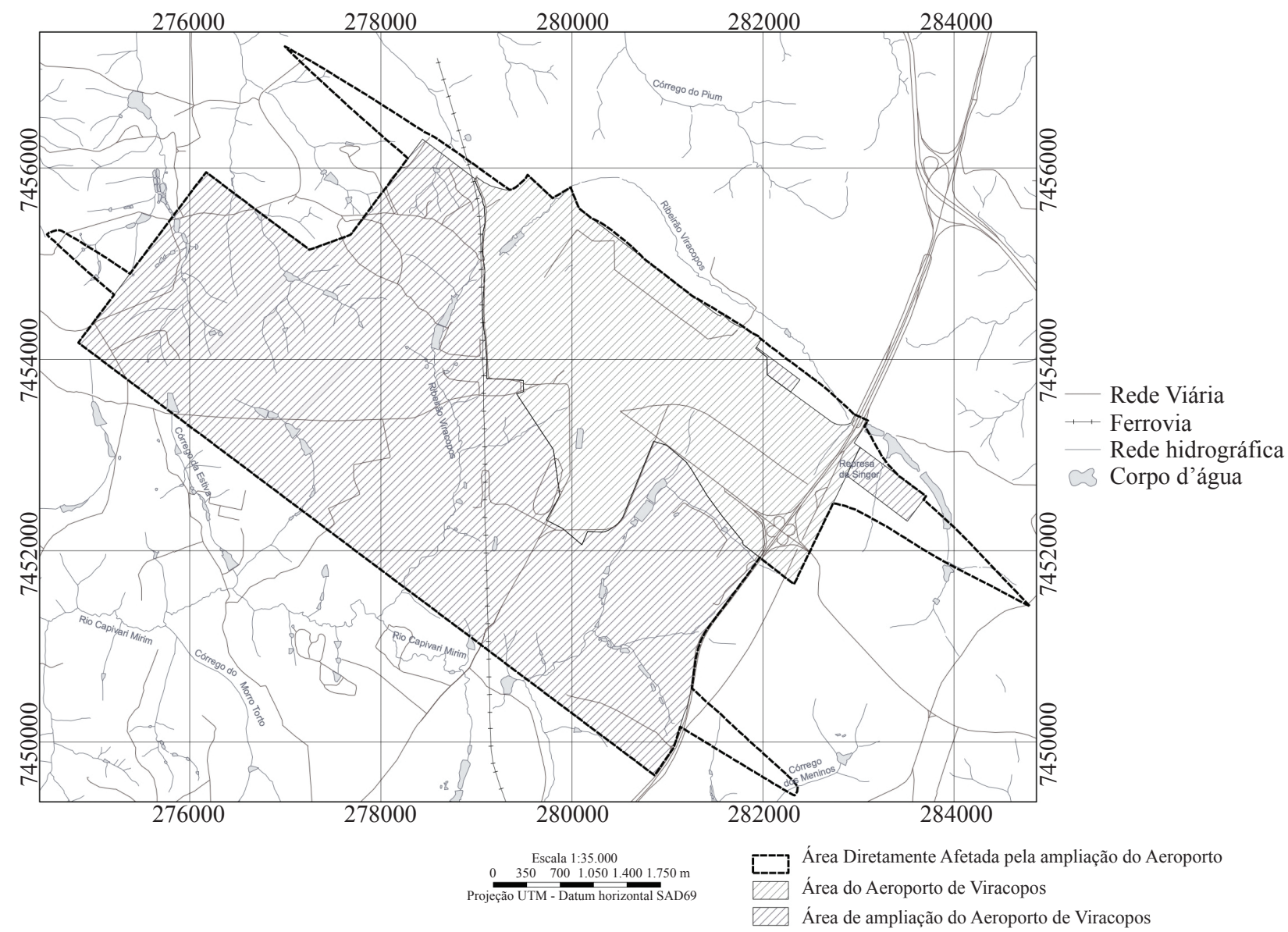

Figura 3 - Hidrografia nas Áreas de Influência do Aeroporto de Viracopos (Walm 2008). 
gerenciamento de riscos ambientais em aeroportos. Para isso, foi realizado um levantamento bibliográfico sobre o assunto, seguido de consultas a documentos técnicos como manuais, normas, planos e programas ambientais em aeroportos brasileiros. Com base nesses dados bibliográficos foram criados indicadores para representar cinco condições que recebem uma pontuação desde o pior cenário (nível 1) até a condição ideal (nível 5), conforme apresentado na Tab. 1.

A segunda etapa (fazer) consistiu na aplicação do método no Aeroporto Internacional de Viracopos, através do levantamento das informações para aplicação dos indicadores por meio da coleta de dados em entrevistas e visitas de campo. Essa etapa contemplou ainda a conversão dos dados obtidos comparando-se a característica apresentada pelo empreendimento, com os cinco cenários possíveis para cada indicador. O cenário que apresentou maior semelhança com a característica do indicador foi selecionado e o respectivo índice atribuído. Os indicadores com os respectivos cenários são apresentados na Tab. 2.

$\mathrm{Na}$ terceira e na quarta etapas (checar e agir) foram analisadas as principais fragilidades no gerenciamento dos riscos ambientais no Aeroporto Internacional de Viracopos. Para isso, foi adotado o modelo de Pressão-Estado-Resposta (OECD 1994). Esse modelo baseia-se em três frentes, a pressão do homem, o estado do meio e a resposta da sociedade, servindo para identificar os prováveis impactos ambientais e definir as estratégias de manejo.

RESULTADOS E DISCUSSÃO Os índices atribuídos aos indicadores para os riscos ambientais são apresentados na Tab. 3. Com base nos resultados apresentados nesta tabela, observa-se que $42 \%$ dos indicadores apresentaram avaliação entre regular a bom, com destaque para o sistema de fumigação, o plano de radioproteção, capacidade dos sistemas de contenção em tanque de combustíveis e as condições das

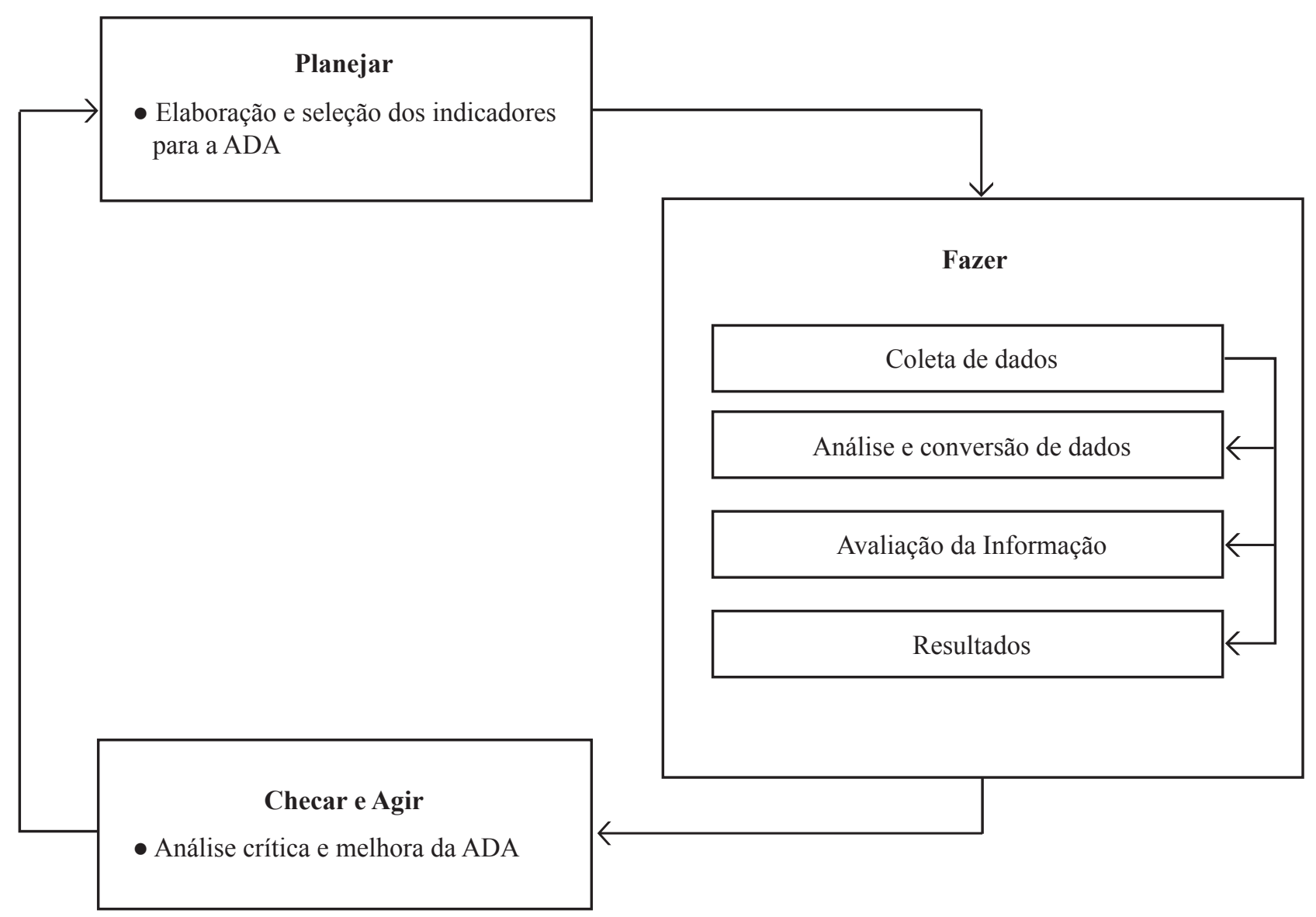

Figura 4 - PDCA - Avaliação de Desempenho Ambiental - ADA (ABNT 2004).

Tabela 1 - Cenário e pontuação para avaliação de riscos ambientais

\begin{tabular}{lccccc}
\hline Cenário/Pontuação & 1 & 2 & 3 & 4 & 5 \\
\hline Avaliação & Ruim & Crítico & Regular & Satisfatório & Bom \\
\hline
\end{tabular}




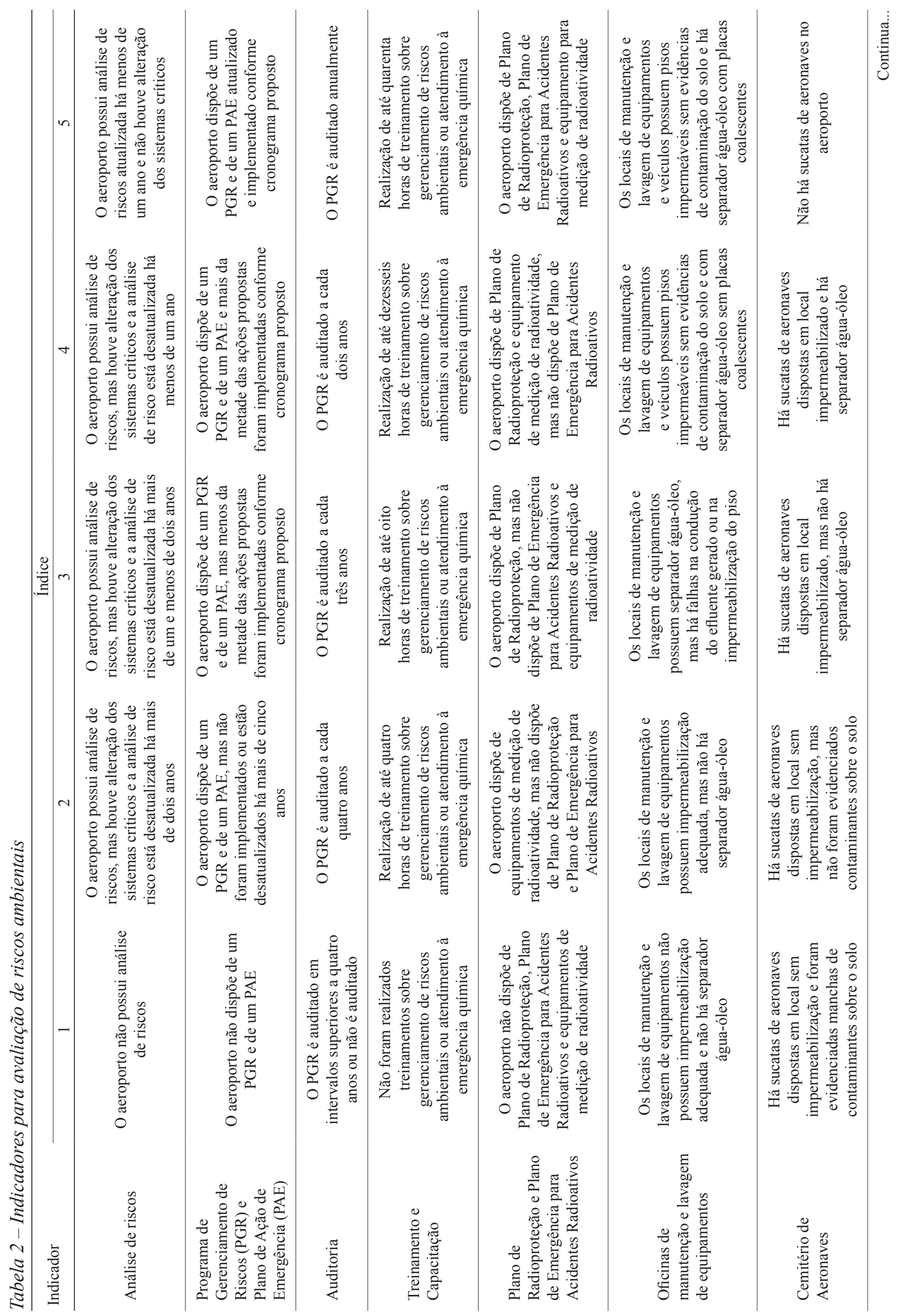




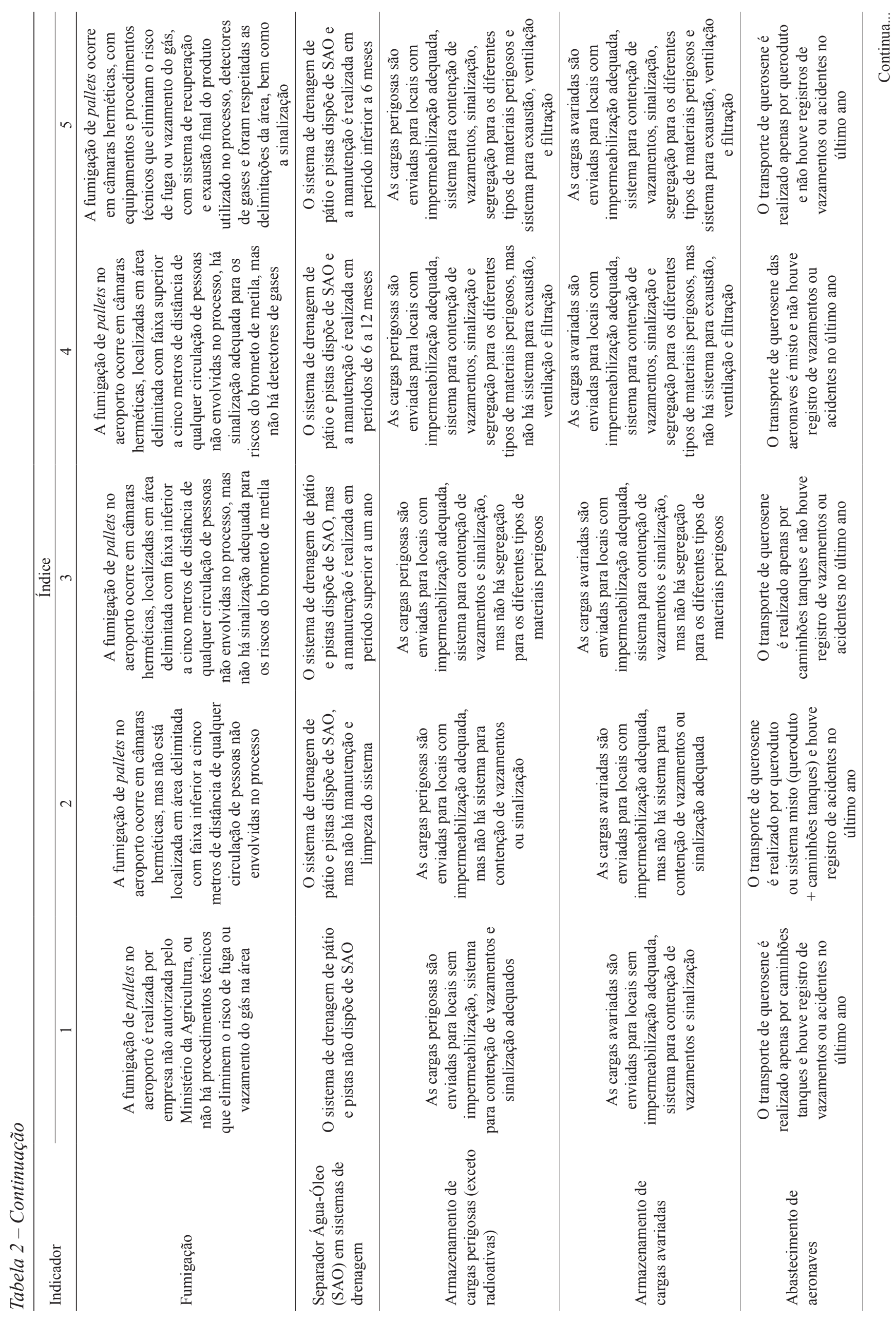




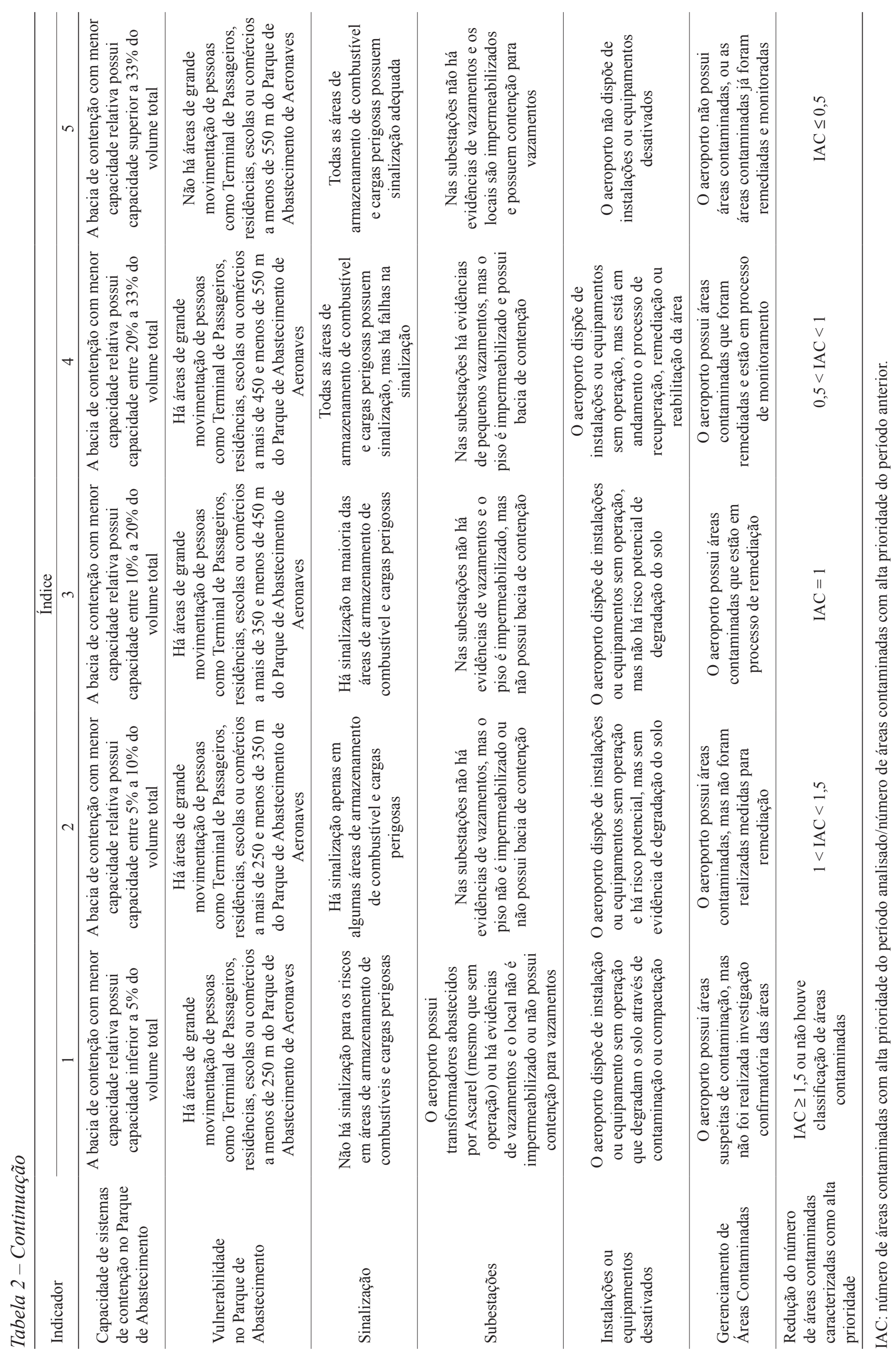


subestações. Assim, dos 58\% restantes, 47\% dos indicadores apresentaram avaliação ruim e $11 \%$ crítico.

Os aeroportos são empreendimentos nos quais ocorrem o armazenamento e manipulação de substâncias perigosas. Assim, os estudos de análise de riscos têm-se mostrado importantes na análise de instalações aeroportuárias já em operação, de modo que os riscos possam ser avaliados e gerenciados a contento. Neste contexto, embora o Aeroporto de Viracopos tenha sido dispensado pela Companhia de Tecnologia de Saneamento Ambiental (CETESB) da elaboração de uma análise de risco no processo de regularização do licenciamento, foi exigida a elaboração e execução de um Programa de Gerenciamento de Riscos (PGR) e um Plano de Ação de Emergência (PAE). Entretanto, até o momento o PGR não foi elaborado e implementado e, consequentemente, também não foram realizados treinamentos e auditorias relacionados ao Programa. Com relação ao PAE, foi apresentado à CETESB o Plano de Emergências Aeronáuticas (PLEM), que compreende parcialmente os aspectos ligados aos atendimentos emergenciais conforme a norma da CETESB P4.261, devendo a administração aeroportuária apenas acrescentar o órgão ambiental no fluxo de acionamentos.

Com relação às cargas radioativas, o antigo terminal de cargas dispõe de uma área específica para esses materiais, com blindagem e sinalização adequadas. Todos os planos e programas de prevenção de riscos são regulamentados pela Comissão
Nacional de Energia Nuclear (CNEN). Dessa maneira, foi elaborado em 2001, o Plano de Radioproteção que contempla as normas e rotinas que visam prevenir e corrigir acidentes com equipamentos, embalados radioativos ou outros envolvendo as instalações do Aeroporto Internacional de Viracopos. Além de descrever todas as ações e responsáveis pelo atendimento às emergências com radioativos, este Plano de Radioproteção inclui os equipamentos mínimos a serem adquiridos pela administração aeroportuária. Em atendimento ao exposto, o Aeroporto de Viracopos possui, por exemplo, um contador Geiger Müller.

No que diz respeito às instalações onde ocorre a manipulação de substâncias perigosas, destacam-se as oficinas de manutenção de equipamentos, as subestações, o cemitério de aeronaves, área para fumigação, armazenamento de cargas e parque de abastecimento. Os locais de manutenção e lavagem de equipamentos de apoio às aeronaves em geral apresentam separador água-óleo, mas há falhas na condução dos efluentes gerados ou na impermeabilização do piso. Além da manutenção dos equipamentos de apoio às aeronaves, na área restrita localizam-se aeronaves sucateadas (Fig. 5), deixadas no local até que ocorra o desmonte e venda das peças. Durante o desmonte pode ocorrer vazamentos de combustível ou óleos presentes na aeronave. Além disso, embora não haja evidências de contaminantes, as aeronaves encontram-se dispostas sobre o solo, sem impermeabilização e/ou caixa separadora água-óleo.

Tabela 3 - Resultados dos indicadores para avaliação de riscos ambientais

\begin{tabular}{lcc}
\hline Indicador & Índice & Desempenho \\
\hline Análise de Riscos & 1 & Ruim \\
\hline Plano de Gerenciamento de Riscos (PGR) e Plano de Ação Emergencial (PAE) & 1 & Ruim \\
\hline Auditorias & 1 & Ruim \\
\hline Treinamento e Capacitação & 1 & Ruim \\
\hline Plano de Radioproteção e Plano de Emergência para Acidentes Radioativos & 4 & Satisfatório \\
\hline Oficinas de manutenção e lavagem de equipamentos & 3 & Regular \\
\hline Cemitério de Aeronaves & 2 & Crítico \\
\hline Fumigação & 5 & Bom \\
\hline Separador Água-Óleo em sistemas de drenagem (SAO) & Regular \\
\hline Armazenamento de cargas perigosas & Crítico \\
\hline Armazenamento de cargas avariadas & Ruim \\
\hline Abastecimento de aeronaves & 2 & Regular \\
\hline Capacidade de sistemas de contenção em tanques de combustível & 1 & Bom \\
\hline Vulnerabilidade no Parque de Abastecimento & 3 & Ruim \\
\hline Sinalização & 5 & Regular \\
\hline Subestações & 1 & Satisfatório \\
\hline Instalações ou equipamentos desativados & 3 & Ruim \\
\hline Gerenciamento de Áreas Contaminadas & 4 & Ruim \\
\hline Redução do número de áreas contaminadas caracterizadas como alta prioridade & 1 & Ruim \\
\hline Média & 1 & 1 \\
\hline
\end{tabular}


Próximo ao chamado cemitério de aeronaves localiza-se a área onde são realizadas as atividades de fumigação. A atividade é realizada por empresa autorizada pelo Ministério da Agricultura, através da aplicação do brometo de metila em câmara de lona. A área é delimitada com faixa superior a cinco metros de distância da circulação de pessoas não envolvidas no processo, com a devida sinalização para os riscos associados à substância aplicada (Fig. 6). Para a realização da fumigação em câmara de lona, estende-se uma lona sobre o piso, fixando-a com o uso de cobras de areia. Posteriormente, deposita-se o material a ser tratado sobre a lona de maneira que a carga forme uma pilha uniforme. Na sequência, estende-se uma lona superior sobre a pilha formada, depositando cobras de areia em todo o perímetro da pilha e introduz-se a ponta da mangueira de aplicação na pilha e aplica-se o gás. Após o período recomendado de tratamento, é feita a sucção do gás, bem como a medição com o detector de gases antes da liberação da carga.

Ainda na área de movimento de aeronaves, o sistema de drenagem de pátio e pistas dispõe de um separador água-óleo com capacidade adequada e manutenção realizada em período superior a um ano. O tanque é de extrema importância por receber as águas drenadas de parte da pista e dos pátios, principalmente provenientes da porção oeste do pátio de aeronaves cargueiras, que contemplam a área destinada à manutenção das aeronaves.

Nos terminais de cargas da INFRAERO ocorre o armazenamento das cargas perigosas, incluindo as radioativas. O local possui pisos impermeabilizados, mas não há sistema para contenção de vazamentos e sinalização adequados. Além disso, embora sejam respeitadas as incompatibilidades entre os diferentes materiais, não há segregação em ambientes específicos para cada classe de substância perigosa. Quando há vazamentos das cargas armazenadas ocorre a identificação do responsável pela carga para retirada e destinação da mercadoria. Caso o responsável não faça o atendimento e retire o material do local, o mesmo é encaminhado para uma área localizada próxima a pista de pouso e decolagem. Embora coberto e com acesso restrito, esse local não possui impermeabilização adequada, bem com sistemas para contenção de vazamentos e sinalização.

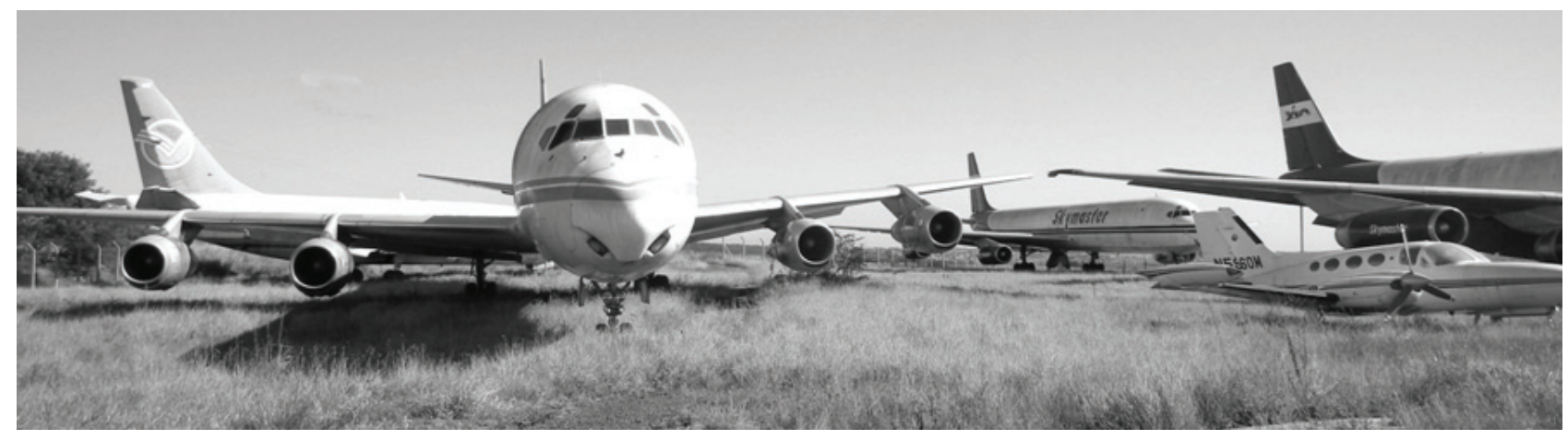

Figura 5 - Cemitério de Aeronaves no Aeroporto Internacional de Viracopos.
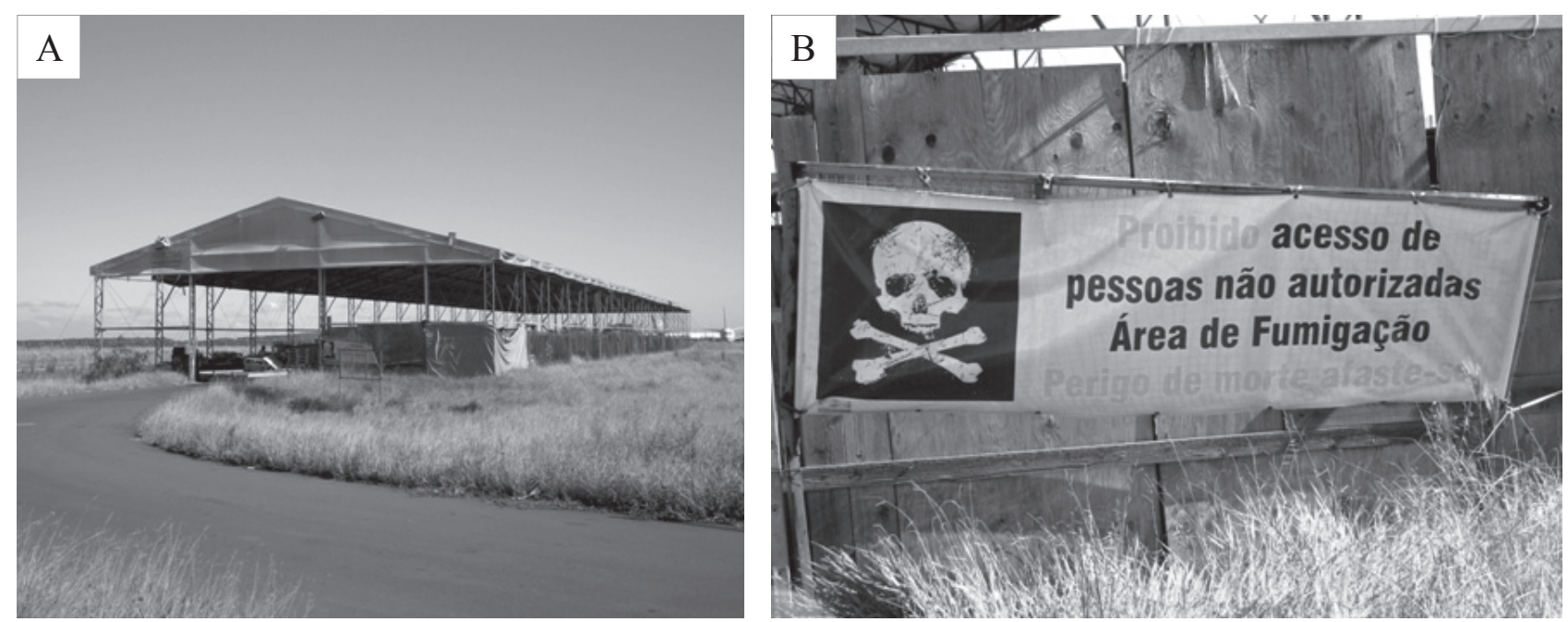

Figura 6 - Galpão de fumigação (A) e sinalização dos riscos associados à fumigação (B). 
No que diz respeito ao abastecimento de aeronaves, o armazenamento de combustível está localizado nos Parques de Abastecimento (Fig. 7). Estes Parques de Abastecimento estão em área de baixa movimentação de pessoas. Entretanto, próximo ao local (menos de $250 \mathrm{~m}$ de distância) há uma escola de educação infantil, o que aumenta a vulnerabilidade da população exposta ao risco. Posteriormente, os caminhões tanques transportam o querosene até as aeronaves para o abastecimento. Embora o aeroporto ainda não disponha de querodutos em operação, o transporte realizado pelos caminhões apresenta-se seguro e não houve registro de acidentes no último ano. Com relação aos tanques de contenção dos Parques de Abastecimento, observa-se a capacidade de $628 \mathrm{~m}^{3}$, ou seja, superior a $33 \%$ do volume total $\left(1200 \mathrm{~m}^{3}\right)$.

As subestações com geradores e transformadores apresentam piso impermeabilizado sem indícios de vazamentos e com bacias de contenção. Outro fator relacionado aos riscos ambientais em aeroportos é a existência de instalações ou equipamentos desativados. No Aeroporto de Viracopos há um antigo canteiro de obras que atualmente é utilizado como instalação para escritórios de empresas. No local, há um tanque e bomba de combustível desativada. Além disso, na área encontra-se grande quantidade de entulho, que acarreta em compactação do solo e possível contaminação. Ainda nas proximidades do canteiro de obras, encontra-se um incinerador desativado, contando também com um tanque de combustível.

Como consequência do armazenamento e manipulação de diversas substâncias perigosas, o Aeroporto de Viracopos realizou em 2010 uma Avaliação Preliminar de Áreas Contaminadas. O estudo contempla a primeira etapa do gerenciamento de áreas contaminadas através da identificação e classificação das áreas potenciais e suspeitas de contaminação. As próximas etapas contemplam a investigação confirmatória, análise de risco, investigação e projeto de remediação. Por fim, pode-se então monitorar as áreas remediadas e reduzir o número de áreas contaminadas caracterizadas como alta prioridade.

\section{ESTRATÉGIAS DE MANEJO E} MONITORAMENTO Os resultados gerados através da avaliação ambiental demonstram que 58\% dos indicadores apresentam avaliação ruim ou crítica. Com base no diagnóstico realizado através da aplicação dos indicadores no Aeroporto Internacional de Viracopos e utilizando-se o modelo de PressãoEstado-Resposta (OECD 1994), foi possível identificar algumas estratégias de manejo e melhoria contínua para as não conformidades identificadas nos indicadores com baixos índices. A pressão existente é relativa ao manuseio e armazenamento de substâncias perigosas, gerando um estado de riso de contaminação do solo e da água. Assim, algumas estratégias de manejo, ou respostas, podem ser propostas:

- Elaborar Estudo de Análise de Risco;

- Elaborar e implementar o Programa de Gerenciamento de Riscos;

- Realizar auditorias e treinamentos sobre riscos ambientais;

- Impermeabilizar e instalar separador água-óleo em oficinas de manutenção e lavagem de equipamentos;

- Adequar o sistema de impermeabilização e o sistema de contenção em subestações;

- Retirar as sucatas de aeronaves;

- Adequar o piso e o sistema de contenção de vazamentos em local para armazenamento de cargas avariadas;

- Realizar armazenamento de cargas perigosas em locais com sistema para contenção de vazamentos, exaustão, ventilação e filtração;

- Realizar Estudo de Viabilidade para instalar querodutos;
A

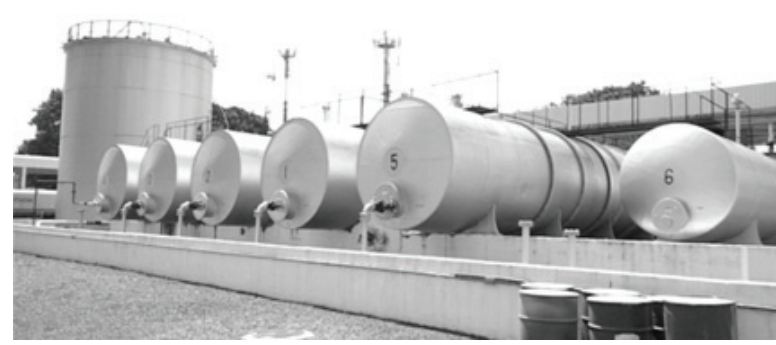

Figura 7 - Tanques aéreos (A) e semienterrados (B) nos Parques de Abastecimento de aeronaves.

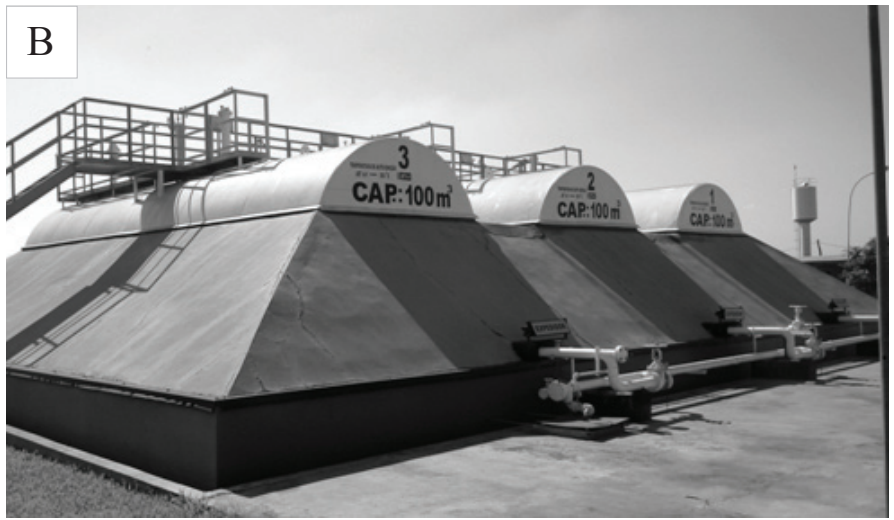


Remover as instalações e os equipamentos desativados;

- Realizar investigação confirmatória de áreas suspeitas de contaminação.

Embora a maioria das mediadas propostas estejam relacionadas às características estruturais do aeroporto, necessitando da realização de obras físicas, as mesmas não representam ações de grandes investimentos. Além disso, as ações propostas não requerem longos períodos de execução, podendo ser realizadas em prazos inferiores há um ano, exceto as atividades contínuas, como as auditorias. Assim, todos esses impactos poderiam ser corrigidos por uma administração aeroportuária mais eficiente em relação à gestão ambiental do Aeroporto Internacional de Viracopos.

Após a realização dessas etapas, esses pontos devem ser monitorados, visto que, para os demais locais, essa fase de monitoramento ambiental periódico já deveria estar sendo realizada, proporcionando um controle eficaz dos recursos naturais encontrados neste aeroporto. $\mathrm{O}$ monitoramento ambiental deve envolver essencialmente a coleta, a análise e a avaliação de dados ambientais para a orientação da melhor maneira de manejo ambiental para o local estudado. As técnicas a serem utilizadas devem estar embasadas em consultas à literatura e debates com profissionais da área ambiental. Esse monitoramento poderá fornecer, ao longo do tempo, uma base de dados para o uso futuro desses recursos naturais, além de determinar se os objetivos das ações de manejo estão produzindo os resultados esperados sem alterar as características do ambiente.

Programas de educação ambiental para população local também devem fazer parte da proposta de minimização dos impactos descritos neste estudo. Estes programas de educação ambiental podem despertar nas pessoas a conscientização dos valores dos ecossistemas encontrados, relacionando os recursos naturais com o cotidiano dos habitantes. Para uma eficiência ainda maior desses programas, atividades educativas devem ser promovidas para as crianças nas escolas e oficinas de trabalhos para a comunidade, sempre com o objetivo de demonstrar que, se bem aproveitados, conservados ou preservados, os recursos do meio ambiente só trazem benefícios para a comunidade.

CONCLUSÕES Diversos aspectos e impactos negativos originados das atividades aeroportuárias estão relacionados à manipulação e armazenamento de substâncias perigosas. Embora pouco aplicado o uso de indicadores, eles podem ser uma ferramenta que permite ampliar a supervisão e a qualidade ambiental. Assim, neste trabalho foi possível desenvolver e aplicar uma avaliação de riscos ambientais em aeroportos, de forma a auxiliar a administração aeroportuária a identificar os aspectos ambientais significativos e as oportunidades para melhorar a gestão.

Neste sentido, foi possível avaliar de forma geral a questão dos riscos ambientais em aeroportos e propor indicadores de desempenho. Tais indicadores apresentaram dados e informações qualitativas e quantitativas referentes aos aspectos e impactos da atividade em questão. A aplicação dos indicadores em um estudo de caso permitiu a obtenção de um desempenho caracterizado como crítico para o gerenciamento dos riscos ambientais no Aeroporto Internacional de Viracopos.

Além disso, o uso dos indicadores associados ao modelo Pressão-Estado-Resposta permitiu a identificação de boas práticas e soluções ambientais para o gerenciamento de riscos. Assim, foram propostas onze ações de resposta às pressões impostas ao meio ambiente, em decorrência da manipulação e armazenamento de substâncias perigosas.

De maneira geral, os indicadores propostos neste trabalho permitiram diagnosticar a gestão dos riscos ambientais no Aeroporto Internacional de Viracopos e fornecer as ações que visam mitigar os impactos negativos associados a sua operacionalidade, possibilitando a apresentação desses resultados de maneira acessível ao público e aos responsáveis pelas tomadas de decisão. Complementarmente, é possível realizar análises comparativas entre aeroportos e acompanhar sistematicamente a evolução do desempenho da gestão de riscos ambientais.

O monitoramento do desempenho do gerenciamento de riscos ambientais poderá fornecer, ao longo do tempo, uma base de dados para acompanhamento das ações realizadas, além de determinar se os objetivos das ações de manejo estão produzindo os resultados esperados. Outro fato interessante é que o desempenho seja divulgado periodicamente, possibilitando às partes interessadas uma análise detalhada dos procedimentos e medidas de controle ambiental adotados. Além disso, os indicadores e suas aplicações servem para auxiliar no planejamento e direcionamento de ações através da identificação de prioridades, sejam elas unidades aeroportuárias ou aspectos ambientais mais críticos. Com isso, podem-se definir as 
preferências em alocação de recursos, reduzir gastos e contribuir para a melhoria contínua do sistema de gestão ambiental de aeroportos.

\section{AGRADECIMENTOS À Coordenação}

de Aperfeiçoamento de Pessoal de Nível Superior
(CAPES), pelo incentivo ao conhecimento científico e aos demais patrocinadores financeiros e intelectuais deste artigo. À INFRAERO e seus colaboradores pelo apoio na realização deste trabalho, em especial para a Engenheira Ambiental Michele Bomback e para o Biólogo Tiago Porto Aranha.

\section{Referências}

ABNT. Associação Brasileira de Normas Técnicas. 2004. NBR 14.031: Gestão Ambiental - Avaliação de Desempenho - Diretrizes. Rio de Janeiro, ABNT.

Ale B.J. M. \& Piers M. 2000. The Assessment and management of third party risk around a major airport. Journal of Hazardous Materials, 71(1-3):1-16.

CAMPINAS. 2006. Lei Complementar $N^{o} 15$ de 27 de Dezembro de 2006. Dispõe sobre o Plano Diretor do Município de Campinas. Diário Oficial do Município de Campinas, Campinas.

CETESB. Companhia Ambiental do Estado de São Paulo. 2003. Norma P4.261: Manual de orientação para a elaboração de Estudos de Análise de Riscos. São Paulo.

INFRAERO. Empresa Brasileira de InfraestruturaAeroportuária. 2011. Estatística dos Aeroportos. Brasília, 2011. Disponível em: http:/www.infraero.gov.br/index.php/br/estatistica-dosaeroportos.html. Acessado em: 21/01/2011.

Johson R. \& Pedoe N.T. 1996. Airfield groundwater contamination - an overview. In: Pedoe N.T., Raper D.W., Holden J.M.W. (eds.). Environmental Management at Airports: liabilities and social responsibilities. Londres, Thomas Telford, p. 130-145.

OACI. Organização Internacional da Aviação Civil. 1991. Airport. Emergency Planning (Doc 9137-AN/898 Part 7). 2. ed. Montreal, OACI.

OECD. Organization for economic co-operation and development. 1994. Environmental Indicators. Paris, OECD Publishing.
Oliveira A.M.S. \& Brito S.N.A. (eds.). 1998. Geologia de Engenharia. São Paulo, Associação Brasileira de Geologia de Engenharia.

Ray S., Khillare P.S., Agarwal T., Shridhal V. 2008. Assessment of PAHs in soil around the international airport in Delhi, India. Journal of Hazardous Materials, 156(1-31):9-16.

Rezende D. \& Merlin S. 2003. Carbono social Agregando valores ao desenvolvimento sustentável. Editora: Peirópolis, Instituto Ecológica. Disponível em: http:/www.socialcarbon.org/uploadDocs/ Documents/Social_Carbon_book_pt.pdf. Acessado em: 24/01/2011.

Santos C.K.N. 2008. Metodologia do carbono social manual do multiplicador. Palmas, Instituto Ecológica.

Struchel A., Cappa A.J., Bernanrdo R. 2008. O Aeroporto Internacional de Viracopos na revisão do Plano Diretor de Campinas - SP em 2006. In: VII Simpósio de Transporte Aéreo. Sitraer, 7:346-357.

Walm - Engenharia e Tecnologia Ambiental. 2008. EIA - Estudo de Impacto Ambiental: Ampliação do Aeroporto Internacional de Viracopos/Campinas - SP, São Paulo, 1:1.1-7.128.

Manuscrito ID 25217

Recebido em: 02/12/2011

Aprovado em: 28/06/2012 